\title{
Trajetória da rubéola no Estado do Pará, Brasil: rumo à erradicação
}

\author{
History of rubella in Pará State, Brazil: towards eradication \\ Trayectoria de la rubéola en el Estado de Pará, Brasil: rumbo a la erradicación
}

Marluce Matos de Moraes

Instituto Evandro Chagas/SVS/MS, Ananindeva, Pará, Brasil

Ana Cecília Ribeiro Cruz

Instituto Evandro Chagas/SVS/MS, Ananindeua, Pará, Brasil

Dorotéa de Fátima Lobato da Silva

Instituto Evandro Chagas/SVS/MS, Ananindeua, Pará, Brasil
Fernanda do Espírito Santo Sagica

Instituto Evandro Chagas/SVS/MS, Ananindeua, Pará, Brasil

Elisabeth Conceição de Oliveira Santos

Instituto Evandro Chagas/SVS/MS, Ananindeva, Pará, Brasil

\section{RESUMO}

Objetivo: Descrever a trajetória da rubéola a partir do perfil soroepidemiológico de indivíduos referenciados ao Instituto Evandro Chagas (IEC) no período de 1989 a 2012, e comparar os resultados antes e após a introdução da vacina contra a rubéola no Estado do Pará, Brasil, pelo programa nacional de imunizações. Metodologia: Estudo retrospectivo com análise de resultados dos testes de dosagem de anticorpos $\lg G$ e $\lg M$ ao vírus da rubéola pelo método de ELISA em 50.439 indivíduos de diferentes faixas etárias, encaminhados ao IEC para investigação diagnóstica de doenças exantemáticas, nos períodos de 1989-1999 (antes da vacina) e 2000-2012 (após a vacina). Resultados: A prevalência da rubéola no estudo mostrou declínio significativo da infecção de $17,26 \%$ para 2,23\% após o período vacinal; a frequência da imunidade aumentou de $48,30 \%$ para $79,39 \%$; a suscetibilidade declinou de $34,54 \%$ para $18,38 \%$. Gestantes infectadas: $9,3 \%$ no período anterior à vacinação e $0,6 \%$ após o período vacinal. Foram registrados 37 casos de síndrome da rubéola congênita (SRC) no período anterior à vacinação, e 11 casos após a vacinação. De 2010 a 2012 não foram registrados casos autóctones da doença e nem de SRC. Conclusão: $\bigcirc$ fortalecimento da vigilância epidemiológica, a capacitação de profissionais da área da saúde nos planos de erradicação com o serviço de sentinela, e as estratégias de campanhas de vacinação, com a introdução da vacina contra a rubéola no esquema de rotina, tiveram significativo impacto na redução dos casos de rubéola e SRC, contribuindo para a erradicação.

Palavras-chave: Rubéola; Síndrome da Rubéola Congênita; Vacina contra Rubéola; Erradicação de Doenças.

\section{INTRODUÇÃO}

O vírus da rubéola (VR) é um membro da família Togaviridae, gênero Rubivirus, apresentando apenas um sorotipo, e causa uma doença exantemática de evolução benigna, exceto na criança em fase de desenvolvimento intrauterino ${ }^{1,2}$. A transmissão ocorre no indivíduo não imunizado, por meio da inalação de aerossóis contendo partículas virais emitidos pelo paciente com rubéola. $O$ período de incubação varia de 12 a 23 dias e, ao final deste período, surge o

\footnotetext{
Correspondência / Correspondence / Correspondencia:

Marluce Matos de Moraes

Instituto Evandro Chagas

Rodovia BR 316, km 7, s/nº. Bairro: Levilândia

CEP: 67030-000 Ananindeua-Pará-Brasil

Tel.: +55 (91) 3214-2217

E-mail:marlucemoraes@iec.pa.gov.br/mlucemoraes@hotmail.com
}

exantema máculo-papular em sentido crânio-caudal e, posteriormente, a linfadenopatia retroauricular e occipital, podendo ocorrer mal estar geral, febre moderada e a disseminação do exantema pelo corpo, regredindo em torno de três dias ${ }^{3,4}$.

Devido à teratogenicidade do vírus, a doença é um grave problema de saúde pública quando a gestante não imunizada é infectada pelo vírus no primeiro trimestre. $O$ feto acometido pelo vírus tem $81 \%$ de chances de desenvolver a síndrome da rubéola congênita (SRC) caracterizada por malformações, prematuridade e abortamento nos casos mais graves ${ }^{5}$.

Estudo de um inquérito sorológico foi realizado pelo Instituto Evandro Chagas (IEC), órgão da Secretaria de Vigilância em Saúde (SVS) do Ministério da Saúde (MS) no período de 1989 a 1999, em mulheres entre 10 a 21 anos de idade, em cinco cidades brasileiras (Belém, Estado do Pará; Recife, Estado de Pernambuco; Goiânia, Estado de Goiás; Niterói, Estado do Rio 
de Janeiro e Porto Alegre, Estado do Rio Grande do Sul), objetivando conhecer o estado imunitário em relação ao VR. Esse estudo serviu como parâmetro para a vigilância epidemiológica do $M S$, que norteou a definição da faixa etária para a campanha de vacinação na época, adotando medidas de controle da ocorrência de surtos de rubéola, a fim de orientar o profissional quanto ao diagnóstico diferencial ${ }^{6}$.

No Brasil, a magnitude do problema da rubéola somente passou a ser reconhecida após a implantação do Plano de Eliminação do Sarampo, em 1992, quando casos suspeitos de sarampo foram diagnosticados como rubéola, que passou a ser doença de notificação compulsória em 19962,7,8.

O MS visando fortalecer a vigilância epidemiológica do sarampo criou, em 1999, um Grupo Tarefa com a designação de um técnico de vigilância do sarampo para cada uma das 27 Unidades Federadas, trabalhando conjuntamente com a vigilância da rubéola/SRC?.

Nos anos de 1999 e 2000, pela primeira vez foram registrados os surtos em municípios paraenses, com 1.224 e 525 casos, respectivamente. Nesse período, a ocorrência da doença afetou mais os níveis etários de 5 a 9 anos (31,4 casos/100.000 habitantes); em seguida os de 1 a 4 anos (28,4 casos/100.00 habitantes); entre 10 a 14 anos (27,8 casos/100.000 habitantes); de 15 a 19 anos (24,8 casos/100.000 habitantes) e de 20 a 29 anos (26,6 casos/100.000 habitantes). Esses surtos ocorreram antes da implantação da vacina tríplice viral (VTV) pelo Programa Nacional de Imunizações ${ }^{10,11}$.

A vacina contra rubéola foi introduzida no Estado do Pará, Brasil, no ano 2000, sendo utilizada a vacina dupla viral (VDV) em crianças de 1 a 11 anos de idade. No ano seguinte, a VTV foi introduzida no esquema de rotina para crianças de 12 meses de idade, com uma dose de reforço entre 4 e 6 anos de idade, substituindo a vacina monovalente do sarampo, que era aplicada aos 9 meses de idade. Nesse mesmo ano foi implantada a Vigilância da Síndrome da Rubéola Congênita no Estado do Pará, com a finalidade de estimar a proporção da ocorrência da SRC e seu efeitos, com o diagnóstico preciso nas crianças com rubéola congênita e garantindo a imunização dos contatos ${ }^{11,12}$.

A campanha de vacinação em mulheres em idade fértil, medida adotada como prevenção da SRC, só ocorreu no Estado do Pará em 2002, com cobertura vacinal de 83\%. No ano de 2006 foi registrada, nos municípios paraenses, $85,1 \%$ de cobertura vacinal, incluindo as mulheres em idade fértil, tendo como consequência a redução da transmissão do VR e consequentemente a SRC, com 18 casos de rubéola e nenhum de SRC10,12.

Após dois anos (2008) ocorreram surtos da doença nos Municípios de Prainha, Parauapebas, Ananindeva e Paragominas, com 108, 35, 34 e 20 casos, respectivamente. $\mathrm{Na}$ Cidade de Belém foram confirmados 15 casos que não foram considerados surto $^{10}$.
Observando o que foi exposto anteriormente, é importante para a história da saúde pública do Estado do Pará, traçar a trajetória da rubéola rumo à erradicação, descrevendo o perfil soroepidemiológico de pacientes referenciados ao IEC, nos momentos anterior e posterior à implementação da vacinação contra a rubéola, visto que o IEC, até o ano de 2002, foi referência nacional para doenças exantemáticas e, após este período, continuou investigando doenças exantemáticas, incluindo a rubéola como diagnóstico diferencial e a imunidade em gestantes no pré-natal, contribuindo para um histórico da epidemiologia de uma doença que, por anos, foi um sério problema de saúde pública, com nascimento de crianças com malformações congênitas, afetadas pela transmissão vertical causada pelo VR.

\section{MATERIAIS E MÉTODOS}

Estudo transversal, retrospectivo, descritivo de uma série histórica, de indivíduos encaminhados por unidades básicas de saúde ao IEC para investigação diagnóstica; realizado por meio de levantamento das fichas arquivadas no banco de dados do IEC, contendo a análise de resultados dos testes de dosagem de anticorpos $\lg G$ e $\lg M$ ao VR pelo método de ELISA em 50.439 indivíduos de diferentes faixas etárias, nos períodos de 1989-1999 (antes da vacina) e 2000-2012 (após a vacina); evolução do quadro clínico; estado vacinal; contatos com doenças exantemáticas e procedência.

Dentre os referenciados estão inclusos os sintomáticos e assintomáticos. Para os sintomáticos que compareciam antes de cinco dias do exantema e - resultado apresentava-se não reativo, era sugerida uma segunda amostra. Os assintomáticos referenciados foram encaminhados após terem contato com doenças exantemáticas; ou eram gestantes no pré-natal, com ou sem contato, para investigação do estado imunológico.

As pesquisas de anticorpos $\lg G$ e $\lg M$ foram realizadas pelo método de ELISA (Enzygnost Anti-Rubella-Virus) utilizando-se kits da Dade Behring ${ }^{\circledR}$, conforme instrução do fabricante. Foram identificadas 50.439 fichas de indivíduos no período de janeiro de 1989 a dezembro de 2012, de menores de 1 ano a maiores de 50 anos de idade, sendo 20.846 no período anterior à vacinação e 29.593 após a implantação da vacinação, residentes no Estado do Pará. A estratificação para análise de mulheres em idade fértil foi de 12 a 45 anos.

Foram considerados como suscetíveis à rubéola os indivíduos com títulos não reativos ao anticorpo lgG específicos para rubéola lgG- e imunes os que apresentaram reatividade com anticorpos $\lg G+$. Os que apresentaram presença de anticorpos $\lg M(+)$ isoladamente ou com a presença de lgG+ foram considerados infectados pelo VR. Nos casos de recémnascidos de mães com diagnóstico confirmados de rubéola e/ou com suspeita de SRC, quando apresentavam lgG reativo, os testes eram repetidos após três meses; se houvesse manutenção do título de lgG, o caso era confirmado; se não, descartado. Em caso 
de dúvida, coletava-se uma terceira amostra, após o mesmo período de três meses, até o esclarecimento do caso.

As variáveis de interesse foram: município de residência, gênero, idade, sintomas que constavam na ficha epidemiológica, data da coleta, estado vacinal e estado sorológico para rubéola.

Para a análise estatística, foi utilizado o teste Qui-quadrado $\left(\chi^{2}\right)$ para amostras independentes por meio dos programas GraphPad Prism 5.0 e BioEstat 5.0, estabelecendo nível de significância com $p<0,05$, bem como o programa Microsoft Excel 2010 para as representações gráficas.

Este estudo foi aprovado em 13 de março de 2009, a partir do parecer $n^{\circ} 0001 / 2009$, protocolo CEP/IEC $n^{\circ}$ 0024/2008, CAAE 0023.0.072.000-08, pelo Comitê de Ética em Pesquisa em Humanos do IEC, sendo assegurada a privacidade das informações e $O$ anonimato dos participantes da pesquisa.

\section{RESULTADOS}

Foram excluídos do estudo pacientes oriundos de outros Estados; pacientes com diagnóstico sorológico para outras viroses exantemáticas, como dengue, sarampo, parvovírus e aqueles com diagnóstico sorológico de toxoplasmose, mononucleose, citomegalovírus e outros, além de participantes do inquérito amostral citado na introdução.

A imunidade contra o VR no período anterior à vacinação representou 48,30\%, e a suscetibilidade, $34,54 \%$ dos casos, enquanto $17,26 \%$ apresentaram infecção sugestiva de rubéola. Após o período vacinal, constatou-se $79,39 \%$ de imunes e 18,38\% suscetíveis, tendo $2,23 \%$ soropositivos para a rubéola $(\lg M+)$. $\bigcirc$ teste Qui-quadrado $\left(\chi^{2}\right)$ demonstrou diferença estatística significante entre as frequências de imunidade, suscetibilidade e infecções recentes pelo VR nos períodos estudados, conforme se demonstra na figura 1 .

No gênero masculino, as maiores frequências de casos ocorreram nas faixas etárias de 1 a 11 anos de idade, tanto no período anterior à vacinação, com $50,5 \%$ (672/1.331), como após a vacinação, com $47,31 \%$ (98/207), sendo que esta distribuição se manteve homogênea (Teste $G: G=5,1930 ; p>0,05$ ). No gênero feminino este padrão não ocorreu, pois a prevalência da infecção pelo VR no período anterior à vacinação foi maior na faixa etária de 1 a 11 anos de idade, com 36,9\% (829/2.247) dos casos, enquanto que após o período vacinal foi observada na faixa etária de 20 a 29 anos de idade, com 28,6\% (123/430), demonstrando distribuição heterogênea em relação ao gênero (Teste $G$ : $G=30,1413 ; p<0,0001$ ).

Comparando o número de casos antes e após a implantação da vacinação, verifica-se diferença estatisticamente significante entre os valores $\left(\chi_{y}^{2}=2009,137 ; p<0,0001\right)$.

No período estudado, a suscetibilidade relacionada ao gênero apresentou diferenças estatísticas ao serem comparados os períodos antes e após a implantação da vacina contra a rubéola, com variação de 55\% para 35\% (Teste Binomial: $Z=21,71$; $p<0,0001$ ) para o gênero masculino, enquanto que para o gênero feminino variou de 36\% para 15\% (Teste Binomial: $Z=45,14 ; p<0,0001)$.

Ao se estratificar apenas as mulheres em idade fértil (12-45 anos) constatou-se que, no período anterior à vacinação, os percentuais de mulheres imunes foram de $76,6 \%(3.734 / 4.874)$ e de suscetíveis $23,4 \%$ (1.140/4.874). Após o período vacinal, $84,8 \%$ (4.304/5.074) estavam imunizadas e 15,2\% (770/5.074) suscetíveis $\left(\chi_{y}^{2}=107,59 ; p<0,0001\right)$, conforme figura 2 .

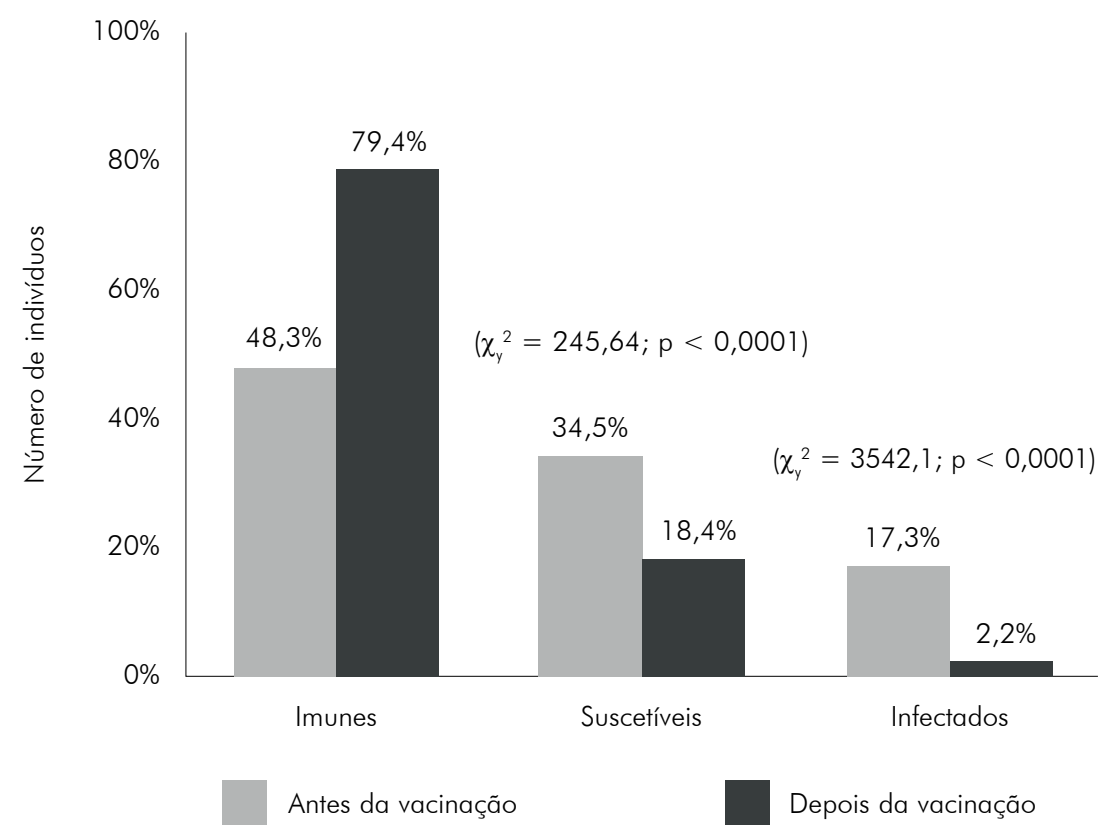

Figura 1 - Distribuição imunológica para rubéola, antes (1989 a 1999) e após (2000 a 2012) a vacinação, Estado do Pará, Brasil 
Entre as gestantes, observou-se no período anterior à vacinação que 8,5\% (272/3.211; IC95\%: 7,5\% - 9,4\%), apresentaram infecção recente pelo VR e após o período vacinal 0,7\% (97/15.401; IC95\%: 0,5\% - 0,8\%), sendo que estas proporções eram estatisticamente diferentes (Teste Binomial: $p<0,001$ ).

Quanto à presença de anticorpo lgG, as frequências também foram diferentes (Teste Binomial: $p<0,0001$ ), pois $67,7 \%$ (2.172/3.211; IC95\%: 66,0\% - 69,3\%) gestantes apresentaram imunidade no período anterior à vacinação e 89,6\% (13.787/15.401; IC95\%: 89,0\% - 90,0\%) após a vacina. Adicionalmente, 23,9\% (767/3.211; IC95\%: 22,4\% - 25,4\%) mostraram-se susceptíveis ao VR antes da vacina e após a vacina, 9,9\% (1.517/15.401; IC95\%: 9,4\% - 10,3\%), conforme se observa na figura 3 .

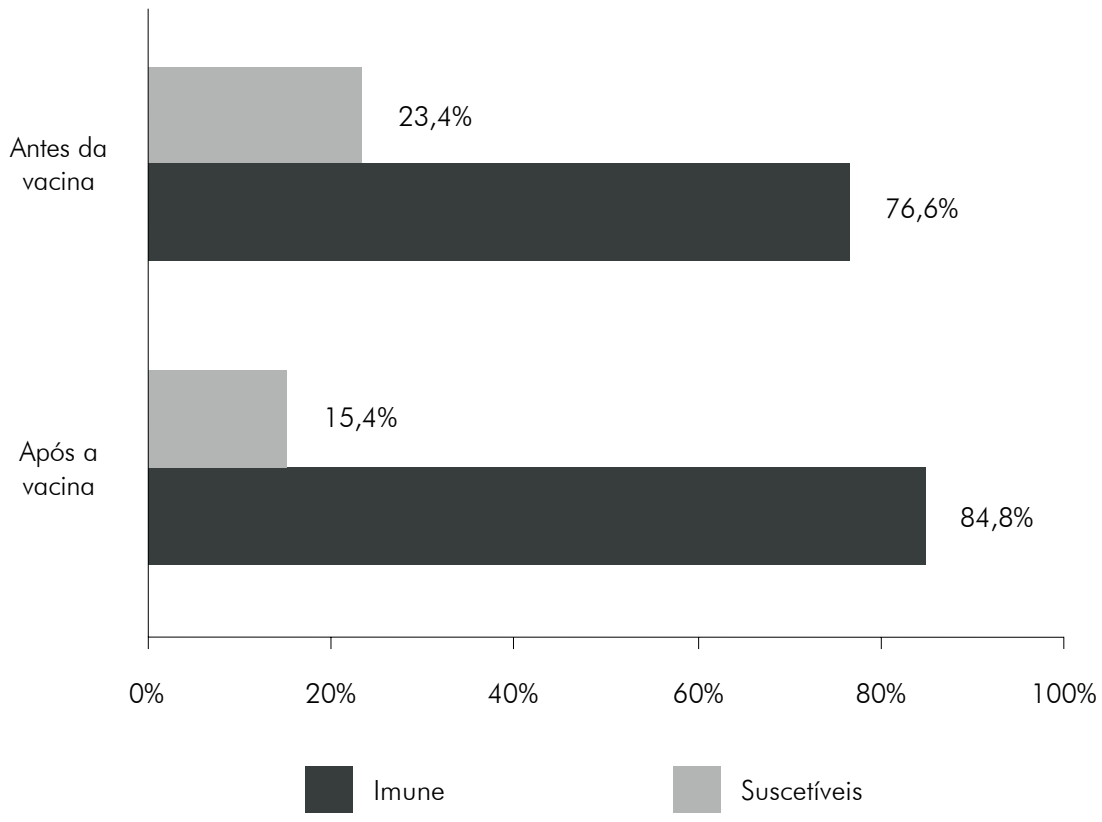

Figura 2 - Proporção imunológica para o VR de mulheres em idade fértil, nas amostras testadas antes (1989 a 1999) e após (2000 a 2012) a vacinação, Estado do Pará, Brasil

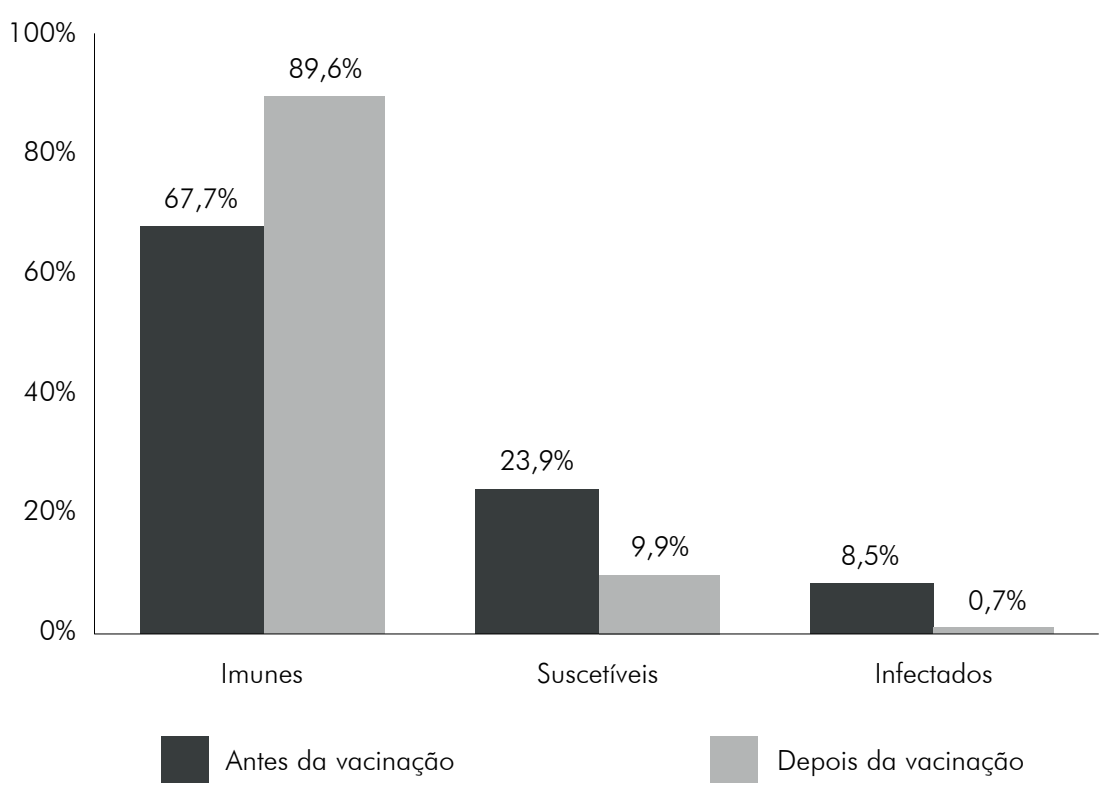

Figura 3 - Distribuição do estado imunológico para o VR, em 2.939 gestantes antes do período vacinal e 15.349 após o período vacinal, atendidas na Seção de Meio Ambiente do IEC/MS, Estado do Pará, Brasil 
estudo demonstrou que, entre os menores de 1 ano de idade com sorologia lgM reagente, a catarata, a cardiopatia e a associação entre estas, foram as manifestações clínicas que mais predominaram no período anterior à vacinação com 11,5\% (6/52), e $9,6 \%$ (5/52), respectivamente. No período após a vacinação, a cardiopatia foi a manifestação mais evidente, com 26,7\% (4/15) dos casos. Verificou-se também que 28,8\% (15/52) e 40,0\% (6/15) dos menores de 1 ano de idade estavam assintomáticos nos períodos antes e depois da vacinação, respectivamente
(Tabela 1). A comparação do número de casos de SRC entre os períodos investigados mostrou que houve diferença significante $\left(\chi^{2}=15,5 ; p<0,0001\right)$.

No ano de 2010 a 2012 foram analisados 20 casos sugestivos para a rubéola que, após investigados, foram descartados, por apresentarem reação cruzada com outra patologia, reação vacinal e persistência do anticorpo lgM (Tabela 2).

Uma série histórica representada na figura 4 mostra a distribuição anual dos casos positivos para rubéola, no período de 1989 a 2012.

Tabela 1 - Distribuição de quadro clínico em menores de um 1 de idade, sugestivos de rubéola congênita, com lgM reativa, nos períodos antes e após a vacinação

\begin{tabular}{|c|c|c|c|c|}
\hline \multirow{2}{*}{ Manifestações clínicas } & \multicolumn{2}{|c|}{ Antes da vacinação } & \multicolumn{2}{|c|}{ Após a vacinação } \\
\hline & $\lg M+$ & $\%$ & $\lg M+$ & $\%$ \\
\hline Cardiopatia + catarata + hepatoesplenomegalia & 1 & 1,9 & - & - \\
\hline Cardiopatia & 5 & 9,6 & 4 & 26,7 \\
\hline Cardiopatia + catarata & 5 & 9,6 & - & - \\
\hline Cardiopatia + catarata + retardo neuropsicomotor + retardamento mental & 1 & 1,9 & - & - \\
\hline Catarata & 6 & 11,5 & - & - \\
\hline Catarata + esplenomegalia & - & - & 1 & 6,7 \\
\hline Catarata + hepatoesplenomegalia + icterícia & 1 & 1,9 & - & - \\
\hline Esplenomegalia + cardiopatia & 1 & 1,9 & - & - \\
\hline Hepatoesplenomegalia + cardiopatia & 1 & 1,9 & - & - \\
\hline Hepatoesplenomegalia + enfartamento ganglionar & 1 & 1,9 & - & - \\
\hline Hepatoesplenomegalia + exantema & 1 & 1,9 & - & - \\
\hline Hepatomegalia & 2 & 3,8 & - & - \\
\hline Hepatoesplenomegalia & - & - & 1 & 6,7 \\
\hline Hepatomegalia + catarata & 1 & 1,9 & - & - \\
\hline Hetapoesplenomegalia + catarata & 1 & 1,9 & - & - \\
\hline Hepatomegalia + retardamento mental + febre & - & - & 1 & 6,7 \\
\hline Icterícia + hepatomegalia + petéquias & 1 & 1,9 & - & - \\
\hline Icterícia & 2 & 3,8 & - & - \\
\hline Icterícia + cardiopatia & 1 & 1,9 & - & - \\
\hline Icterícia + hepatoesplenomegalia & 1 & 1,9 & 1 & 6,7 \\
\hline Microcefalia & 2 & 3,8 & - & - \\
\hline Microcefalia + cardiopatia & - & - & 1 & 6,7 \\
\hline Microcefalia + cardiopatia + catarata & - & - & 1 & 6,7 \\
\hline Retardamento mental + retardo neuropsicomotor & 1 & 1,9 & - & - \\
\hline Retardamento mental + retardo neuropsicomotor + hepatoesplenomegalia & 1 & 1,9 & - & - \\
\hline Retardo neuropsicomotor & 1 & 1,9 & - & - \\
\hline Assintomático & 15 & 28,8 & 6 & 40,0 \\
\hline Total & 52 & 100,0 & 16 & 100,0 \\
\hline
\end{tabular}


Tabela 2 - Anticorpos lgM reagentes que não foram considerados infecção pelo VR, observados em crianças, adultos e gestantes no período de 2010 a 2012

\begin{tabular}{lcccc}
\hline \multicolumn{1}{c}{ Causa } & Grupos & Adulto & Total \\
\hline Infecção cruzada & Criança & Gestante & A & 2 \\
Toxoplasmose & 1 & 1 & - & 1 \\
Citomegalovírus & - & - & 1 & 1 \\
HIV & - & - & - & 1 \\
Dengue & 1 & - & - & 2 \\
Varicela & 2 & - & - & 7 \\
Reação vacinal & 7 & - & 2 & 6 \\
Persistência do anticorpo lgM & - & 7 & 20 \\
\hline Total & 11 & 7 & 2 \\
\hline
\end{tabular}

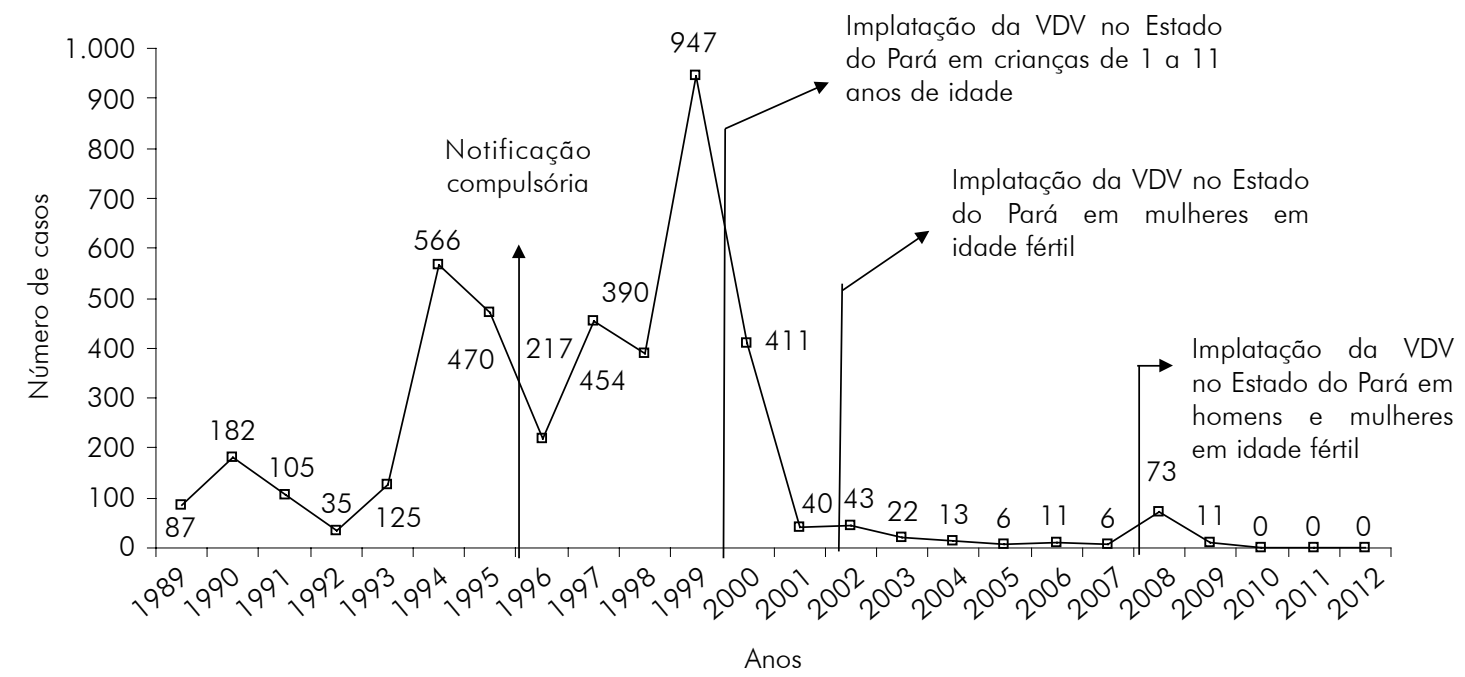

Figura 4 - Casos de rubéola diagnosticados no IEC/SVS/MS, Estado do Pará, 1989-2012

\section{DISCUSSÃO}

Este estudo traça a trajetória da rubéola no Estado do Pará rumo à erradicação, por meio do perfil soroepidemiológico, em estudo de uma série histórica de 24 anos, comparando o período anterior e posterior à implantação da vacinação pelo Programa Nacional de Imunização.

Dentre as 50.439 amostras coletadas para identificação do VR, 54\% representaram a capital (Belém) e 46\% o interior do Estado do Pará. Comparando os dois períodos, é notável que a frequência de indivíduos imunes tenha aumentado de $48,3 \%$ para $79,4 \%$ após a vacinação e, em consequência, a significante diminuição de suscetíveis, de $34,5 \%$ para $18,4 \%$, mostrando a importância da imunização, corroborando o estudo de Segatto et $a^{13}$, quando descreveram 0 impacto das campanhas de vacinação na eliminação da rubéola no Brasil.

Ao avaliarmos a distribuição do número de casos, estratificando por faixa etária, observamos que as crianças de 1 a 11 anos de idade, no período anterior à vacinação, em ambos os gêneros, foram os que apresentaram as maiores frequências de acometimento da infecção pelo VR. Entretanto, após a introdução da vacinação com a dupla viral em 2000 no Estado do Pará que contemplou crianças de 1 a 11 anos de idade, prevaleceu a frequência no gênero masculino, porém no gênero feminino a infecção teve um deslocamento de faixa etária para adultos jovens de 20 a 29 anos de idade. Cardoso e Guedes ${ }^{14}$ também citam em seu estudo este deslocamento de faixa etária após estratégia de vacinação.

Comparando a proporção de número de casos de rubéola entre os períodos antes e após a vacinação, verifica-se uma diminuição significante da infecção em torno de $80 \%$, refletindo o resultado da campanha de vacinação de 2008, quando contemplou o gênero masculino' ${ }^{12}$.

Ao observarmos somente o período anterior à vacinação, verificamos o índice de suscetibilidade de $34,5 \%$, maior do que os valores encontrados no estudo de Schatzmayr e Mesquita ${ }^{15}$ no Rio de Janeiro, Estado do Rio de Janeiro que observaram índices de 20,0\%, bem como no trabalho de Estrela ${ }^{16}$, em Porto Alegre, no Estado do Rio Grande do Sul que registrou 19,0\% de suscetíveis. 
No presente estudo, a imunidade no período posterior à vacina $(79,4 \%)$ foi maior e a suscetibilidade menor $(18,4 \%)$ do que no estudo de Fernandez et $\mathrm{al}^{17}$, em Natal, Estado do Rio Grande do Norte, que revelou imunidade de $65,6 \%$ e suscetibilidade de $34,4 \%$.

Sintetizando o estudo, observou-se que houve aumento dos percentuais de imunidade e consequentemente a diminuição da suscetibilidade, com diferença significante entre os períodos. Entretanto, os homens mostraram-se mais vulneráveis à doença do que as mulheres, principalmente porque a campanha de vacinação contemplou crianças e mulheres em idade fértil, sendo que somente em 2008 a campanha expandiu-se para homens e mulheres. Castillo-Solórzano et al $^{18}$ relataram que, na Costa Rica e em Honduras, a vacinação ocorreu tanto em mulheres quanto nos homens com idades entre 5 e 39 anos, o que se constitui em uma estratégia rápida para o controle da doença, interrompendo a transmissão do VR.

As mulheres em idade fértil têm sido o principal alvo das campanhas de vacinação, pois é muito importante que elas tenham consciência de fazer a imunização pelo menos um mês antes de engravidar, uma vez que não existe tratamento para evitar o dano no feto. Ao apresentarem imunidade, não correm o risco de contrair a rubéola, e assim evitam as consequências dos problemas teratogênicos em seus conceptos, como malformações e até mesmo um aborto. Neste estudo constatou-se que, no período anterior à vacinação, os percentuais de mulheres imunes foram de $76,6 \%$ e de suscetíveis $23,4 \%$.

Após o período vacinal, a proporção de mulheres imunes aumentou significativamente, sendo que $84,8 \%$ estavam imunizadas e 15,2\% suscetíveis. Em estudo semelhante, realizado em Goiânia em 1978 por Ishak et $\mathrm{al}^{19}$, a prevalência de anticorpos para o VR em mulheres em idade fértil foi de $89,8 \%$ e a suscetibilidade 10,2\%, percentuais que, em nosso estudo, nem após a imunização foram alcançados.

Uma vez que a rubéola é uma patologia muitas vezes subclínica, a gestante não tem conhecimento de estar contraindo ou não a infecção, o que pode gerar desconhecimento da causa de abortos ou fetos com malformações. Nas gestantes deste estudo, a imunidade foi de $67,7 \%$ no período anterior à vacina e $89,6 \%$ após o período da vacinação, resultados inferiores ao encontrados por Steibel et $a^{20}$, que verificaram, em seu estudo, a prevalência de $\mathrm{lg} G$ em gestantes em Porto Alegre com frequência de 97,0\%. Constatou-se, no presente estudo que no período anterior à vacina, $23,9 \%$ das gestantes estavam suscetíveis ao VR e, após a vacina, 9,9\%; e que em ambos os períodos, a suscetibilidade prevaleceu na faixa etária de 12 aos 29 anos de idade. Em relação ao período pós-vacinal de nosso estudo, autores como Barros et al ${ }^{21}$ encontraram, na Cidade de São Paulo, Estado de São Paulo, taxas maiores de suscetibilidade: 22,79\%. Quando analisada a presença de $\lg M$ reagente nas gestantes neste estudo, detectou-se a taxa de $8,5 \%$ no período anterior à vacinação e $0,7 \%$ após o período vacinal. grande problema de $\lg M$ reativa em sorologia de gestante no pré-natal é identificar com segurança se a infecção é recente, primária, reinfecção, um falso positivo, uma infecção cruzada, ou ainda persistência prolongada do anticorpo $\operatorname{lgM}$. É importante a anamnese para o esclarecimento diagnóstico, em busca de informações como contato com doenças exantemáticas, imunização recente e sorologia realizada em outros prénatais anteriores. Recomenda-se o acompanhamento da gestante com outras sorologias e indicar o teste de avidez, porém este não foi utilizado em nosso estudo.

$\bigcirc$ esclarecimento diagnóstico é imprescindível, visto que a transmissão no primeiro trimestre de gravidez pode levar dano ao feto. É importante a orientação ao casal, pois no Brasil, a interrupção da gravidez nesses casos não é permitida, segundo o Conselho Federal de Medicina ${ }^{22}$.

risco de malformações após a infecção por rubéola no primeiro trimestre, segundo Monteleone e Valente ${ }^{23}$, é de 7,4\% a 28\% e o Ministério da Saúde registrou, em situações de surto, a SRC em recém-nascidos na proporção de 4,3/1.000 nascidos vivos.

Foram identificados, neste estudo, 20 casos que apresentaram $\lg M$ reativo, porém não foram considerados casos de infecção pelo VR. $\mathrm{Na}$ investigação foi constatada reação vacinal, infecção cruzada e persistência do anticorpo lgM. Antes da erradicação da rubéola, reações sorológicas com resultados de $\lg M$ e $\lg G$ reativas eram interpretadas como infecções agudas, as quais, em gestante, são consideradas de risco para a transmissão do agente infeccioso para o feto. Essa interpretação deixou de ser adotada, pois estudos de Hedman e Seppala ${ }^{24}$ e de Hedman e Rousseau ${ }^{25}$ mostraram que os anticorpos $\lg M$ podem persistir por vários meses na corrente sanguínea e, em alguns casos, até um a dois anos, e, por isso, sugerem ser realizado o teste de avidez. Thomas et $a^{26}$ relataram em seu estudo que muitos quadros de virose podem sofrer interferência do fator reumatoide, ocasionando falsos positivos.

Como a rubéola é uma das patologias do diagnóstico diferencial do sarampo, no ano de 1993, metade dos casos descartados para sarampo confirmaram rubéola, caracterizando um surto da doença no Brasil e, como consequência, um número significativo de casos de crianças com SRC.

Neste estudo, os recém-nascidos que apresentaram ao nascimento $\lg M$ reagente não foram relacionados com a mãe, pois o banco de dados não permitiu essa correlação de mãe-filho. Ao observarmos a $\lg M$ reagente no período anterior à vacinação e o quadro clínico apresentado por menores de 1 ano de idade, verificamos que a cardiopatia e a catarata predominaram. Nesse período foram identificados 37 casos sugestivos de SRC e 15 crianças portadoras de rubéola congênita, pois estavam assintomáticos e sem problemas congênitos. Após o período vacinal, dez casos apresentaram manifestações clínicas sugestivas de SRC, sendo que a manifestação clínica predominante foi a cardiopatia, isolada ou em associação com 
a catarata, e seis crianças demonstraram serem portadoras de infecção congênita, contudo sem sintomatologia. Houve concordância com o estudo de Gregg $^{27}$ que, em seu trabalho clássico, citou que os defeitos mais frequentes foram malformações cardíacas, alterações oculares e auditivas associadas ou não ao retardo mental e a microcefalia. No entanto, neste estudo não foi identificada deficiência auditiva; isso pode ser explicado pelo fato de ser uma manifestação tardia. Segundo Tonelli e Freire ${ }^{28}$, as manifestações tardias podem ocorrer isoladamente ou com outras patologias, após o segundo ano de vida até a idade escolar da criança.

É importante a identificação da patologia pelos profissionais de saúde e pelos pais, em todos os casos confirmados e suspeitos de rubéola congênita, o mais precocemente possível, para evitar a disseminação do vírus, visto que o portador pode estar expelindo o vírus por um período considerado para a transmissão de mais ou menos um ano.

Doenças associadas à imunidade para a rubéola como diabetes, disfunção tireoidiana, hipertensão arterial, entre outras, que interferem no desenvolvimento e que surgem tardiamente, têm sido reportadas como rubéola congênita ${ }^{29}$.

Por meio de uma série histórica apresentada na figura 4, podemos verificar que, no período anterior à vacina, houve aumento do número de casos em 1994, 1997 e 1999, com 566, 454 e 947 casos, respectivamente. Após a vacinação, observou-se declínio significante com discreta elevação em 2002, outra ainda maior em 2008, no mês de julho, sendo considerado surto, com 73 casos em Prainha, no interior do Estado do Pará, registrando maior percentual para o gênero masculino. Em agosto ocorreu a campanha de vacinação para a rubéola, contemplando tanto as mulheres com idade de 20 a 39 anos como os homens, tendo como resultado diminuição do número de casos nos demais anos do estudo, visto que o Estado do Pará alcançou uma cobertura de $97 \%{ }^{12}$.

Uma limitação em nosso trabalho merece comentário, por se tratar de estudo retrospectivo, utilizando um banco de dados em que informações de algumas variáveis não estavam disponíveis. Por exemplo, não foi possível estabelecer correlação de mãe-filho nos casos de recém-nascidos que apresentaram ao nascimento anticorpos $\lg M$. Entretanto, a análise do banco permitiu traçar um perfil soroepidemiológico da patologia estudada apontando decréscimo significativo de suscetíveis, refletindo as ações e estratégias da vigilância epidemiológica rumo à erradicação da rubéola e SRC, documentando esta trajetória no Estado do Pará.

\section{CONCLUSÃO}

A descrição do perfil soroepidemiológico proposta por este trabalho mostrou a trajetória da rubéola rumo à erradicação no Estado do Pará, comparando o período anterior ao posterior à vacinação, abrangendo 24 anos, sendo possível detectar o declínio significativo da infecção pelo VR e, em consequência, a diminuição da SRC, indicando a possibilidade de erradicação.

Com a descoberta de casos de rubéola em suspeitos de sarampo, sentiu-se a necessidade de incluir também a rubéola no Plano de Erradicação do Sarampo. Foi quando, em 1999, a Organização Pan-Americana da Saúde (OPAS) elaborou uma estratégia acelerada de controle da rubéola e prevenção da SRC para o continente americano, envolvendo todos os níveis de governo - federal, estadual e municipal - para assumirem compromissos e prioridades com as ações e estratégias do Plano de Erradicação do Sarampo e Rubéola, frente à meta proposta, direcionando recursos humanos, financeiros e materiais necessários para a vigilância epidemiológica, assegurando o abastecimento de vacinas para fortalecer as ações básicas. Nesse mesmo ano, o Centro Nacional de Epidemiologia do MS implementou o Grupo Tarefa, investindo em recursos humanos financiado pela OPAS, seguindo com experiências de campanhas de vacinação em massa, capacitação de pessoal, monitoramento e investigação de casos.

Erradicar doenças em um país como o Brasil é um grande desafio, visto a dimensão continental que possui e as deficiências dos meios de acesso a vilarejos e vicinais nos interiores dos Estados. Apesar de todas as dificuldades, o Brasil vacinou o maior número de pessoas nas Américas, segundo comentário de Brendan Flannery, consultor da $\mathrm{OPAS}^{30}$, que relatou ainda que os últimos casos registrados decorrentes da importação do vírus são um sinal de que a vigilância em saúde funciona e o Brasil tem como comprovar a não circulação das doenças.

acompanhamento da vigilância epidemiológica com medidas de profilaxia mudou no decorrer do período a prevalência da doença. Segundo Nota Técnica $\mathrm{n}^{\circ} 21$, do MS, a OPAS certificou o Brasil, em 2010, como país sem circulação do VR por mais de 12 meses, porém recomenda o monitoramento de viajantes nos últimos 30 dias e dos que apresentarem clínica compatível e vínculo epidemiológico com a patologia. É válido lembrar que, apesar do êxito das campanhas nacionais de vacinação em massa ainda encontramos suscetíveis e com a entrada de estrangeiros no Brasil em decorrência do evento internacional das Olimpíadas Mundiais em 2016, devemos ficar em alerta, pois será necessária uma vigilância contínua em aeroportos, bem como em pessoas que apresentarem quadro clínico suspeito da referida patologia, visto que a rubéola está erradicada apenas no Brasil ${ }^{31}$.

\section{AGRADECIMENTOS}

Agradecemos às pesquisadoras $\mathrm{dr}^{\text {as }}$ Iracina de Jesus e Heloisa Marcelino, pelo apoio logístico; aos técnicos do Laboratório de Virologia da Seção de Meio Ambiente do IEC/SVS/MS, Antonio Carlos, Airton Teixeira e Ritângela Santos pela coleta e realização dos ensaios; e à Luciana Melo, pela dedicação em alimentar o banco de dados. 


\section{History of rubella in Pará State, Brazil: towards eradication}

\section{ABSTRACT}

Objective: To describe the rubella trajectory using seroepidemiological profile of individuals referred to Instituto Evandro Chagas (IEC) between 1989 and 2012, and to compare the results before and after rubella vaccine introduction in Pará State, Brazil, through the National Immunization Program. Methods: Retrospective study analyzing the results of tests for detection of $\lg G$ and $\lg M$ antibodies to rubella virus by ELISA method in 50,439 individuals from different age groups, who were directed to IEC for diagnosis of exanthematous diseases in 1989-1999 (before the vaccine), and 2000-2012 (after the vaccine). Results: The rubella prevalence in this study presented a relevant decrease in infection from $17.26 \%$ to $2.23 \%$ after the vaccination period; immunity frequency increased from $48.30 \%$ to $79.39 \%$; susceptibility was reduced from $34.54 \%$ to $18.38 \%$. Infected pregnant women were $9.3 \%$ before the vaccination period and $0.6 \%$ after the vaccination period. A total of 37 cases of congenital rubella syndrome (CRS) were recorded in the prevaccination period, and 11 after it. From 2010 to 2012, there were no records of autochthonous cases of either that disease or CRS. Conclusion: Strengthening of epidemiological surveillance, training for health professionals in eradication plans with monitoring services, and vaccination strategies with the introduction of rubella vaccine in the routine schedule had a great impact on reducing rubella and CRS cases, contributing to eradication.

Keywords: Rubella; Rubella Syndrome, Congenital; Rubella Vaccine; Disease Eradication.

\section{Trayectoria de la rubéola en el Estado de Pará, Brasil: rumbo a la erradicación}

\section{RESUMEN}

Objetivo: Describir la trayectoria de la rubéola a partir del perfil seroepidemiológico de individuos referenciados al Instituto Evandro Chagas (IEC) en el período de 1989 a 2012, y comparar los resultados antes y después de la introducción de la vacuna antirrubéola en el Estado de Pará, Brasil, por el programa nacional de inmunizaciones. Metodología: Estudio retrospectivo con análisis de resultados de las pruebas de dosis de anticuerpos $\lg G$ e $\lg M$ al virus de la rubéola por el método de ELISA en 50.439 individuos de diferentes franjas etarias, encaminados al IEC para investigación diagnóstica de enfermedades exantemáticas, en los períodos de 1989-1999 (antes de la vacuna) y 2000-2012 (después de la vacuna). Resultados: La prevalencia de la rubéola en el estudio mostró una disminución significativa de la infección de 17,26\% para 2,23\% luego del período de vacunación; la frecuencia de la inmunidad aumentó de $48,30 \%$ para $79,39 \%$; la susceptibilidad disminuyó de 34,54\% para 18,38\%. Gestantes infectadas: 9,3\% en el período anterior a la vacunación y $0,6 \%$ después del período de vacunación. Registrados 37 casos de síndrome de rubéola congénita (SRC) en el período anterior a la vacunación, y 11 casos luego de la vacunación. De 2010 a 2012 no se registraron casos autóctonos de la enfermedad, ni tampoco de SRC. Conclusión: El fortalecimiento de la vigilancia epidemiológica, la capacitación de profesionales del área de salud en los planes de erradicación con el servicio de centinela, las estrategias de campañas de vacunación con la introducción de la vacuna antirrubéola en el esquema de rutina tuvieran un significativo impacto en la reducción de los casos de rubéola y SRC, contribuyendo para la erradicación.

Palabras clave: Rubéola; Síndrome de Rubéola Congénita; Vacuna contra la Rubéola; Erradicación de la Enfermedad.

\section{REFERÊNCIAS}

1 Banatvala JE, Brown DWG. Rubella. Lancet. 2004 Apr;363(9415):1 127-37.

2 Ministério da Saúde (BR). Secretaria de Vigilância em Saúde. Exantemáticas: manual de vigilância para erradicação do sarampo, controle da rubéola e eliminação da síndrome da rubéola congênita. 3 . ed. Brasília: Ministério da Saúde; 2003.

3 Chantler J, Wolinsky JS, Tingle A. Rubella virus. In: Knipe DM, Howley PM, editors. Fields virology. 4th ed. Philadelphia: Lippincott, Williams \& Wilkins; 2001. p. 963-90.
4 Chernesky MA, Mahony JB. Rubella virus. In: Murray PR, Baron EJ, Pfaller MA, Tenover FC, Yolken RH, editors. Manual of clinical microbiology. 7th ed. Washington: American Society for Microbiology; 1999. p. 964-9.

5 Plotkin SA, Reef S. Rubella vaccine. In: Plotkin SA, Orenstein WA, editors. Vaccines. 4th ed. Philadelphia: Elsevier; 2004. p. 707-43.

6 Souza OS, Santos ECO, Serruya SJ. Rubéola. In: Leão RNQ, coordenador. Doenças infecciosas e parasitárias: enfoque amazônico. Belém: Cejup; 1997. p. 395-409. 
7 Brasil. Ministério da Saúde. Portaria $n^{\circ} 1.100$, de 24 de maio de 1996. Define a relação de doenças de notificação compulsória para todo o território nacional. Diário Oficial da União, Brasília, p. 9133, 27 mai. 1996. Seção 1.

8 Ministério da Saúde (BR). Fundação Nacional de Saúde. Guia de vigilância epidemiológica: influenza/ varíola. 5. ed. Vol. 2. Brasília: Funasa; 2002.

9 Santos ED. Avaliação do impacto das estratégias e prevenção e controle da rubéola e da síndrome da rubéola congênita nos estados de São Paulo, Paraná, Rio Grande do Norte, Goiás e Pará, 19922003 [dissertação]. Rio de Janeiro: Escola Nacional de Saúde Pública Sergio Arouca, Fundação Oswaldo Cruz; 2005.

10 Pará. Secretaria Executiva de Saúde. Indicadores de saúde. Inf Epidemiol Sus (Pará). 2007 jan-jun;6(1):1.

11 Ministério da Saúde (BR). Tópicos de saúde: rubéola [Internet]. 2007 [citado 2007 jun 26]. Disponível em: http://portal.saude.gov.br/portal/ saude/visualizar_texto.cfm? idtxt $=22343$.

12 Ministério da Saúde (BR). Secretaria de Vigilância em Saúde. Departamento de Vigilância Epidemiológica. Brasil livre da rubéola: campanha nacional de vacinação para eliminação da rubéola, Brasil, 2008: relatório. Brasília: Ministério da Saúde; 2009. 196 p.

13 Segatto TCV, Barros FR, Silva MM, Pereira MCCQ, Santos ED. Impacto das campanhas de vacinação na eliminação da rubéola e na síndrome da rubéola congênita: Brasil, 1997-2005. Brasília: Ministério da Saúde; 2005.

14 Cardoso FTP, Guedes JPF. Perfil epidemiológico da rubéola no Distrito Federal [Internet]. In: $5^{\text {a }}$ Mostra e Produção Científica da Coordenação de Pós-Graduação Lato Sensu da PUC Goiás - Saúde; 2010 out 22; Goiânia: PUC-GO; 2010 [citado 2012 out 22]. p. 1-18. Disponível em: http://www.cpgls.ucg. br/ArquivosUpload/1/File/V\%20MOSTRA\%20DE\%20 PRODUO\%20CIENTIFICA/SAUDE/51.pdf.

15 Schatzmayr HG, Mesquita JA. Papel do laboratório de análise clínica no controle de casos da infecção pelo vírus da rubéola. Bol Epidemiol Minist Saude. 1997;4:10.

16 Estrela VMA. Anticorpos para rubéola em Porto Alegre: em mulheres de 20 a 40 anos. Rev Inst Med Trop Sao Paulo. 1974 nov-dez; 16(6):337-40.

17 Fernandez JV, Meisser RV, Brito MHHF, Fonseca SMD, Fernandez TAAM, Luz KG, et al. Estudo sorológico sobre rubéola em Natal - RN. Rev Med Minas Gerais. 2004 jul-set;14(3):142-6.

18 Castillo-Solórzano C, Carrasco P, Tambini G, Reef S, Brana M, Quadros A. New horizons in the control of rubella in prevention of congenital rubella syndrome in the Americas. J Infect Dis. 2003;187 Suppl 1:S146-57.
19 Ishak R, Leão JE, Cardoso DDP, Fernandes OFL. Prevalência de anticorpos para rubéola em um segmento da população feminina, gestante ou não, em Goiânia. Rev Inst Med Trop Sao Paulo. 1981 jul-ago;23(4):139-42.

20 Steibel G, Milan C, Steibel JAP, Cunha Filho EV, Torrens MC, Stucky JM. Prevalência de anticorpos lgG para rubéola em gestantes do Hospital São Lucas da PUCRS, Porto Alegre, Brasil. Sci Med. 2007 jul-set; 17(3): 11 5-8.

21 Barros SMO, Lacava RMV, Lima MBO. Susceptibilidade à rubéola entre gestantes: prevalência e intervenções de enfermagem. Acta Paul Enferm. 2001 jan-abr;14(1):54-61.

22 Conselho Federal de Medicina (BR). Resolução $\mathrm{n}^{\circ}$ 1.989, de maio de 2012 [Internet]. 2012 [citado 2014 fev 26]. Disponível em: http://www.portalmedico.org. br/resolucoes/CFM/2012/1989_2012.pdf.

23 Monteleone PPR, Valente CA. Infectologia em ginecologia e obstetrícia. São Paulo: Atheneu; 1997. $384 \mathrm{p}$.

24 Hedman K, Seppala I. Recent rubella virus infection indicated by a low avidity of specific lgG. J Clin Immunol. 1988 May;8(3):214-21.

25 Hedman K, Rousseau SA. Measurement of avidity of specific $\mathrm{lgG}$ for verification of recent primary rubella. J Med Virol. 1989 Apr;27(4):288-92.

26 Thomas HIJ, Morgan-Capner P, Roberts A, Hesketh L. Persistent rubella-specific IgM reactivity in the absence of recent primary rubella and rubella reinfection. J Med Virol. 1992 Mar;36(3):188-92.

27 Gregg NMA. Congenital cataract following German measles in the mother. Trans Ophthalmol Soc Aust. $1941 ; 3: 35-46$.

28 Tonelli E, Freire LMS. Doenças infecciosas na infância e adolescência. 2. ed. Rio de Janeiro: Medsi; 2000. Rubéola; p. 882-902.

29 Altman A, Szyper-Kravitz M, Agmon-Levin N, Gilburd $B$, Anaja JM, Barzilai $O$, et al. Prevalence of rubella serum antibody in autoimmune diseases. Rev Bras Reumatol. 2012 May-Jun;52(3):307-18.

30 Ministério da Saúde (BR). Secretaria de Vigilância em Saúde. Nota Técnica n 21/2011/URI/ CGDT/DEVEP/SUS/MS, de 8 de junho 2011. Recomendação para não realização de exames de rotina para rubéola em gestante. Brasília: Ministério da Saúde; 2011.2 p.

31 Ministério da Saúde (BR). Erradicação do sarampo e da rubéola no Brasil deve ser comprovada até dezembro [Internet]. 2011 [citado 2012 set 30]. Disponível em: http://portal. saude.gov.br/portal/aplicacoes/noticias/default. cfm? pg =dspDetalheNoticia\&id_area $=1498 \& C O$ NOTICIA $=13347$.

Recebido em / Received / Recibido en: 7/4/2014 Aceito em / Accepted / Aceito en: 2/10/2014 